\title{
DESKRIPSI TINGKAT KECEMASAN REMAJA PUTRI YANG MENGALAMI MENARCH DI SMP ISLAM TERPADU KHOLISATURRAHMI BINJAI
}

\author{
Leny Suarni \\ Akademi Keperawatan Sehat Binjai \\ Email: lenysuarni2016@gmail.com
}

\begin{abstract}
Menarche is the first mestruasi blood expenditure, the arrival of menarche can cause positive or negative reactions, a positive reaction if the individual is able to appreciate, understand and accept menarche as a sign of maturity that is owned by a woman otherwise a negative reaction will cause anxiety. Anxiety is a condition where an individual or group experiences anxiety (judgment or opinion) and autonomic nervous system activity in responding to threats that are unclear, non specific. The purpose of this research is to determine the level of anxiety of adolescents facing menarche in Islam Integrated Junior Highschool Khalisaturrahmi Binjai, mild anxiety level, moderate anxiety level, severe anxiety level. The type of research used is descriptive. The population in this study amounted to 32 respondents. The sample in this study amounted to 24 respondents with consecutive sampling techniques. The results showed that respondents experienced mild anxiety levels of 12 people (50\%), 8 people (33\%) moderate anxiety and 4 people (17\%) with severe anxiety. From the results of the study it can be concluded that the level of anxiety of adolescents facing menarche in Islam Integrated Junior High School School Khalisaturrahmi Binjai majority in the category of mild anxiety levels, amounting to 12 respondents or (50\%). Further researchers are advised to conduct research on the handling of anxiety in young women in the face of menarche.
\end{abstract}

Keywords: anxiety, adolescents, menarche, moderate anxiety, severe anxiety

\section{PENDAHULUAN}

Masa remaja merupakan masa yang sangat penting dalam perkembangan seseorang dan merupakan masa peralihan dari masa kanak-kanak ke masa dewasa yang disebut juga masa pubertas. Periode pubertas inilah akan terjadi percepatan pertumbuhan dan perkembangan fisik, serta mengalami kematangan organ reproduksi seksual, ditandai oleh pertumbuhan fisik yang cepat, menarche, perubahan psikologis dan timbulnya ciri- ciri kelamin sekunder (Al-mighwar, 2011).
Menurut Nugraha (2011) data demografi menunjukkan bahwa penduduk didunia jumlah populasi remaja merupakan populasi yang besar. Berdasarkan World Health Organization (2017) umur remaja berkisar antara 10-19 tahun, dengan ratarata usia menarche 13 tahun. Sekitar Sembilan ratus juta berada dinegara sedang berkembang. Di Indonesia gadis remaja pada waktu menarche bervariasi antara 1016 tahun dan rata-rata menarche 12,5 tahun, usia menarche lebih dini di daerah perkotaan dari pada yang tinggal di desa dan lebih lambat pada wanita yang kerja 
berat (Wiknjosastro, 2002). Di Kota Medan, anak-anak perempuan mengalami menarche rata - rata umur $11-14$ tahun bahkan ada yang mengalaminya menarche umur 9 tahun di waktu kelas 4 SD, yang seperti itu bisa tergolong earlymaturation (Harpenas et. el, 2012). Hal ini karena anak perempuan tersebut menggalami kematangan fisik secara dini. Menurut Fauzi (2017) Menarche merupakan perdarahan pertama kali dari uterus yang terjadi pada wanita di masa pubertas sekitar usia 10-15 tahun. Pada periode waktu menuju menarche akan terjadi masa yang dinamakan premenarche. Premenarche adalah sekelompok gejala fisik maupun tingkah laku yang timbul dan disusul dengan periode tanpa gejala. Perubahan sikap sebelum menarche diantaranya cemas, ketegangan dan gugup, cepat marah, berat badan bertambah, edema pada ekstrimitas, payudara sakit, abdomen terasa penuh, nafsu makan meningkat, ingin makan makanan manis, depresi, cepat lupa dan bingung.

Menarche merupakan mestruasi pertama biasanya terjadi dalam rentang usia 10-16 yang tahun atau pada masa awal remaja di tengah pubertas sebelum memasuki masa reproduksi (Proverawati dkk., 2009). Mansur (2014) mengatakan menarche adalah pengeluaran darah mestruasi pertama reaksi remaja terhadap datangnya menstruasi pertama terbagi menjadi dua macam, yaitu reaksi positif dan reaksi negatif. Seorang individu disebut menunjukkan reaksi positif jika individu tersebut mampu menghargai, memahami dan menerima menstruasi pertama sebagai suatu tanda kedewasaan yang dimiliki seorang wanita. Sedangkan bagi remaja putri yang sudah mengetahui dan sudah mendapatkan informasi tentang akan datangnya mestruasi maka mereka tidak akan mengalami kecemasan malahan menganggap hal itu sebagai suatu proses yang alami dan merupakan kodrat wanita, tetapi bila mereka kurang memperoleh informasi maka remaja putri akan merasa pengalaman yang negatif bagi dirinya.

Melihat permasalahan ini perlu dilakukan pemberian informasi tentang menarche bertujuan membantu remaja mempersiapkan diri dalam menghadapi menarche (Nurmawati dkk., 2016). Psikologis remaja harus dipersiapkan untuk menghadapi menarche sehingga remaja dapat menghadapi proses menarche dengan sehat. Pemberian informasi mengenai sedini mungkin merupakan salah satu bentuk persiapan untuk remaja. Tujuan pemberian informasi ini adalah agar remaja tahu bahwa menarche adalah tanda seorang anak perempuan beralih menjadi dewasa.

Hal ini sejalan dengan penelitian Wijayanti dkk., (2013) mengatakan ada hubungan antara pengetahuan remaja tentang menarche dengan kecemasan 
menghadapi menarche di SD TLOGO Kasihan Bantul dan SD Mejing II Yogyakarta bahwa remaja yang memiliki pengetahuan baik sebagian besar memiliki kecemasan sedang dalam menghadapi menarche sebanyak 8 orang $(66,7 \%)$. Remaja yang memiliki pengetahuan cukup memiliki kecemasan sedang dalam menghadapi menarche sebanyak 8 orang $(47,1 \%)$. Remaja yang memiliki pengetahuan kurang memiliki kecemasan berat dalam menghadapi menarche sebanyak 3 orang (60\%), hal ini ditunjukan dengan nilai pvalue $0,037<0,05$. Dengan keerataan hubungan rendah 0,315 .

Menurut Kurniawan (2009) remaja putri yang mempunyai kecenderungan nerotis dalam usia pubertas, banyak mengalami konflik batin dari datangnya menstruasi pertama yang dapat menimbulkan beberapa tingkah laku patologis, meliputi kecemasan berupa phobia, wujud minat yang sangat berlebih, rasa berdosa atau bersalah yang sangat ekstrim yang kemudian menjelma menjadi reaksi paranoid.

Kecemasan merupakan respon individu terhadap suatu keadaan yang tidak menyenangkan yang dialami oleh setiap makluk hidup dalam kehidupan sehari hari (Purba 2010). Kecemasan sebagai rangsangan melalui sistem saraf di teruskan melalui saraf pusat yaitu limbic sistem melalui transmisi saraf, selanjutnya melalui saraf autonom (simpatis atau parasimpatis) akan diteruskan di kelenjar-kelenjar hormonal (endrokin) hingga mengeluarkan secret (cairan) neurohormonal menuju hipofisis melalui sistem prontal guna mengeluarkan gonadotropin dalam bentuk FSH (Follikel Stimulazing Hormone dan LH (Leutinizing Hormone).

Kecemasan adalah ketegangan, rasa tidak aman dan khawatir yang timbul karena dirasakan terjadinya sesuatu yang tidak menyenangkan, tetapi sumbernya sebagian besar tidak diketahui dan berasal dari dalam (Hendro, 2006). Kecemasan adalah hasil dari proses psikologis, sosial atau fisik dalam pengembangan kecemasan. Gejala yang sering terjadi dan sangat mencolok pada peristiwa haid pertama ialah kecemasan atau ketakutan, diperkuat oleh keinginan untuk menolak proses fisiologis. Kadang-kadang pada saat itu timbul pula sikap menyalahkan ibunya, mengapa ibunya melahirkan dirinya sebagai wanita dalam kondisi "genangan dosa" yang harus ditebusnya dengan siklus menstruasi setiap bulan. Dan timbullah rasa bersalah dan berdosa, serta fantasi-fantasi yang tidak rill dalam mengenai proses haid. Lalu menggangap peristiwa haid sebagai suatu bencana atau sebagai suatu proses penembusan dosa (Kartono,1992).

Menurut Ferika (2016) faktor kecemasan yang mempengaruhi dalam menghadapi menarche antara lain 
pengetahuan, usia menarche, dukungan ibu, sumber informasi, ketidaksiapan. Sebagaimana Hasil penelitian Abadi dkk (2015) ada hubungan yang signifikan antara dukungan keluarga dengan tingkat kecemasan remaja putri dalam menghadapi menarche dengan nilai $\rho$-value $=0,007<(\alpha$ $=0,05)$.

Berdasarkan survei awal yang dilakukan peneliti didapatkan 5 siswa dari 6 siswi mengatakan cemas, gelisah, gugup dan ada perasaan takut akan menghadapi menarche dan 1 siswi mengatakan bingung menghadapi menarche, merasa gugup dan cemas, rasa takut saat menghadapi haid pertama kali, kurang fokus saat belajar pada haid pertama kali, tidak nyaman saat duduk kurang percaya diri. pada saat baru pertama kali haid,dan responden merasakan khawatir. 1 orang mengatakan takut dan cemas menghadapi menarche karena segala sesuatu yang diperbuat sudah ditanggung dosa sendiri. Selama ini responden mengatakan tidak mendapat penjelasan dari keluarga maupun guru di sekolah. Oleh karena itu maka rumusan masalah penelitian adalah bagaimana tingkat kecemasan remaja dalam menghadapi menarche di SMP IT Khalisaturrahmi Binjai?. Tujuan penelitian menguraikan tingkat kecemasan pada remaja yang mengalami menarche di SMP Islam Terpadu Kholisaturrahmi Binjai.

\section{METODE PENELITIAN}

Metode penelitian yang digunakan dalam penelitian ini adalah survei deskriptif digunakan untuk menggambarkan atau memotret masalah kesehatan serta yang terkait dengan kesehatan sekelompok penduduk atau orang yang tinggal dalam komunitas tertentu (Notoarmodjo, 2012). Populasi pada penelitian ini adalah siswi kelas SMP IT Khalisaturrahmi Binjai berjumlah 32 orang. Teknik pengambilan sampel dalam penelitian ini adalah consecutive sampling. Teknik ini, maka populasi memiliki kesempatan yang sama untuk dilakukan penelitian yang memenuhi kriteria inklusi yang dijadikan sampel penelitian (Sastroasmoro, 2007).

Kriteria inklusi dalam penelitian ini adalah siswi SMP IT Khalisaturrahmi Binjai yang belum menstruasi yang hadir saat penelitian dilakukan, bersedia dijadikan responden. Kriteria eksklusi meliputi tidak hadir pada saat penelitian dilakukan, dan tidak bersedia dijadikan responden. Jumlah sampel yang memenuhi kriteria berjumlah 24 orang. Dalam penelitian ini hanya menggunakan satu variabel yaitu tingkat kecemasan saja. Instrumen yang dipakai yaitu HARS (Hammilton Anxiety Rating Scale).

\section{HASIL}

Hasil penelitian berdasarkan tingkat kecemasan remaja menghadapi menarche 
Di SMP IT Khalisaturrahmi Binjai Tahun 2019 dapat dilihat pada data berikut:

Tabel 1 Distribusi Frekuensi Karakteristik Responden Berdasarkan Umur

\begin{tabular}{rcc}
\hline Umur & $\begin{array}{c}\text { Frekuensi } \\
(\mathbf{n})\end{array}$ & $\begin{array}{c}\text { Persentase } \\
(\%)\end{array}$ \\
\hline 11 tahun & 6 & 25 \\
12 tahun & 6 & 25 \\
13 tahun & 10 & 41,7 \\
14 tahun & 2 & 8,3 \\
\hline Total & 36 & 100,0 \\
\hline
\end{tabular}

Berdasarkan tabel 1 menunjukkan bahwa dari 24 responden, mayoritas responden berumur 13 tahun berjumlah 10 siswi $(41,7 \%)$, kemudian responden yang berumur 11 tahun berjumlah 6 siswi (25\%) serta responden yang 12 tahun berjumlah 2 siswi (25\%) dan responden yang berumur 14 tahun berjumlah 2 siswi $(8,3 \%)$.

Tabel 2 Distribusi Tingkat Kecemasan Remaja Menghadapi Menarche

\begin{tabular}{lcc}
\hline $\begin{array}{l}\text { Tingkat } \\
\text { kecemasan }\end{array}$ & Frekuensi & $\%$ \\
\hline Ringan & 12 & 50 \\
Sedang & 8 & 33 \\
Berat & 4 & 17 \\
Panik & - & - \\
\hline Total & 24 & $100 \%$ \\
\hline \multicolumn{1}{c}{ Berdasarkan } & hasil & penelitian,
\end{tabular}

didapatkan data yang disajikan dalam tabel 2 diatas dapat diketahui bahwa remaja putri di SMP IT Khalisaturrahmi Binjai dari 24 responden bahwa responden memiliki tingkat kecemasan ringan adalah 12 orang (50\%), tingkat kecemasan sedang 8 orang $(33 \%)$ dan tingkat kecemasan berat 4 orang $(17 \%)$.

\section{PEMBAHASAN}

Hasil penelitian diperoleh bahwa dari 24 responden, mayoritas responden berumur 13 tahun berjumlah 10 siswi (41,7\%). Penelitian ini didukung dengan hasil penelitian yang dilakukan Retnaningsih dkk., (2016) kesiapan menghadapi menarche dengan tingkat kecemasan pada anak usia sekolah bahwa mayoritas responden yang mengalami menarche di SD Negeri Plalangan 01 Semarang pada umur 12 tahun sebanyak 12 orang $(33,3 \%)$. Hal ini sejalan World Health Organization (2017) umur remaja berkisar antara 10-19 tahun, dengan ratarata usia menarche 13 tahun.

Hasil penelitian diperoleh bahwa kecemasan responden mayoritas pada tingkat kecemasan ringan sebanyak 12 orang $(50 \%)$. Hal ini karena responden merasa gugup dan cemas ketika pertama kali haid, rasa takut saat menghadapi haid pertama kali, kurang fokus perhatian terhadap apapun saat mengalami haid pertama kali, tapi akhirnya responden merasakan baik-baik saja setelah mengalami haid pertama kali. Hasil penelitian yang sama Suyamti dan Hastuti (2015) yang berjudul: gambaran tingkat kecemasan remaja putri kelas VII dan VIII bahwa dari 80 responden yang mengalami pubertas mayoritas mengalami tingkat kecemasan ringan dengan jumlah 56 orang (70\%), 21 orang $(26,3 \%)$ mengalami cemas 
sedang dan 3 orang $(3,8 \%)$ remaja putri mengalami kecemasan berat. Hasil penelitian ini diperkuat dengan pendapat Stuart dan Suddeen (1998) bahwa kecemasan ringan berhubungan dengan ketegangan dalam kehidupan sehari-hari. Tingkat ini seseorang lebih waspada dan lapangan persepsinya meningkat seperti melihat, mendengar dan gerakan menggenggam lebih kuat. Tingkatan ini dapat memberi motivasi untuk belajar dan meningkatkan perkemban gan seseorang.

Menurut Suryani dan Widyasih (2008) sikap remaja putri yang menghadapi menarche cenderung menggambarkan rasa cemasnya yang paling tinggi. Hal ini sejalan dengan Brizendine bahwa remaja perempuan lebih mungkin mengalami kecemasan terutama pada usia reproduktif, terutama saat perempuan menghadapi menarche (Batubara 2010). Hasil penelitian diperoleh dari 24 responden sebanyak 8 orang (33\%) pada tingkat kecemasan sedang. Temuan penelitian: bahwa responden merasa gugup dan cemas ketika pertama kali haid, karena beberapa sebab seperti: rasa takut saat menghadapi haid pertama kali, kurang fokus perhatian terhadap apapun saat mengalami haid pertama kali, dan kadang mimpi buruk yang berkaitan dengan situasi menstruasi pertama kali, pada saat menggunakan pembalut membuat duduk tidak nyaman, dan tidak bisa tenang dan kurang percaya diri pada saat baru pertama kali haid, dan sebagian responden merasakan khawatir sampai tangan basah dan berkeringat ketika menggalami haid pertama kali.

Kecemasan yang dialami oleh responden karena kurangnya informasi dan informasi yang salah tentang menarche yang menyebabkan ketidaknyamanan dan kehawatiran pada saat menstruasi pertama atau menarche. Pernyataan ini sejalan dengan Hawari (2004) menyatakan bahwa kecemasan sedang berhubungan dengan adanya kecemasan yang ditandai dengan corak atau tipe kepribadian pencemas, yaitu antara lain Cemas, khawatir, tidak tenang, ragu dan bimbang. Pernyataan ini didukung dengan hasil penelitian Fauzi dan Irfan (2017) Gambaran Tingkat Kecemasan Remaja Putri Menghadapi Menarche di MTS Nurul Fata yaitu sebagian besar remaja putri $(70 \%)$ dengan kecemasan sedang dan sebagian kecil (30\%) remaja putri dengan kecemasan berat. Hasil penelitian ini diperkuat oleh Rifrianti (2013) tentang tingkat kecemasan siswi dalam menghadapi menarche di SMP Warga Surakarta tahun 2013 dari 35 siswi didapatkan hasil tingkat cemas sedang sebanyak 17 responden $(48,6 \%)$ hal ini karena kurangnya pengetahuan mengenai menarche yang mengakibatkanan reaksi emosional pada berbagai kekhawatiran.

Menurut Agustin (2009) kecemasan 
remaja putri dalam menghadapi menstruasi pertama (menarche) adalah suatu perasaan tidak menentu dan bisa menjadi saat yang menyusahkan, seringkali diikuti perasaan yang campur aduk, takut dan cemas serta membingungkan. Hal ini umumnya disebabkan karena kurang atau salahnya informasi mengenai menstruasi. Ketidaktahuannya dapat menyebabkannya secara keliru menghubungkan haid dengan penyakit atau luka bahkan memandangnya sebagai sesuatu yang memalukan, karena tidak mendapatkan penjelasan yang benar.

Hasil penelitian diperoleh dari 24 responden sebanyak 4 orang (17\%) pada tingkat kecemasan berat. Hal ini karena merasa gugup dan cemas ketika pertama kali haid, rasa takut saat menghadapi haid pertama kali, kurang fokus perhatian terhadap apapun saat mengalami haid pertama kali, dan kadang kadang mimpi buruk yang berkaitan dengan situasi menstruasi pertama kali, pada saast menggunakan pembalut membuat duduk tidak nyaman, dan tidak bisa tenang dan kurang percaya diri pada sat baru pertama kali haid,dan sebagian responden merasakan khawatir sampai tangan basah dan berkeringat ketika menggalami haid pertama kali. Selain itu responden juga merasa jantung berdetak cepat ketika pertama kali haid, dan merasa pusing saat menggalami haid pertama kali. Hal ini terjadi karena kurangnya informasi tentang menarche dari guru di sekolah maupun keluarga dan pandangan yang salah sehingga menimbulkan kecemasan dalam menghadapi menarche.

Hasil penelitian ini sejalan dengan pendapat Stuart dan Sundeen (1998) bahwa lapangan persepsi individu sangat sempit. Dengan tanda dan gejala, napas pendek, nadi dan tekanan darah naik, rasa tertekan, nyeri dada, agitasi, berkeringat, sakit kepala penglihatan kabur dan tegang, tidak perhatian pada sesuatu, pemecahan masalah yang digunakan efektif, dan butuh seseorang, perasaan terancam meningkat, perasaan tidak berdaya, munculnya tingkah laku yang tidak sesuai. Hasil penelitian yang sama oleh Renaningsih dkk., (2016) dari 36 responden di SD $\mathrm{N}$ Plalangan 01 Semarang, dengan pvalue $(0,026)<0,05$. Hasil tidak siap dengan cemas berat sebanyak 13 siswi $(36,1 \%)$, mengalami kecemasan berat dikarenakan kesiapan yang rendah sehingga menimbulkan reaksi kecemasan yang tinggi. Menurut Suryani dan Widyasih (2008), yaitu Kesiapan anak dalam menghadapi menarche semakin muda usia anak, maka akan semakin ia belum siap menerima menarche karena menganggap hal itu sebagai beban.

Menurut teori model keperawatan Calista Roy faktor yang dapat mempengaruhi kecemasan remaja putri 
dalam menghadapi menarche yaitu tingkat pengetahuan, remaja putri yang mempunyai pengetahuan baik tentang menarche, akan mudah memahami perubahan fisiologis yang menyebabkan ketidakstabilan kondisi psikologis, sehingga ia dapat mengantisipasi atau mengatasi kecemasan menghadapi menarche. Sebaliknya Saringendyanti (2001) mengatakan remaja putri yang kurang mengetahui tentang menarche maka mudah mengalami kecemasan. Usia yang masih sangat muda merupakan ketidaksiapan remaja putri menerimanya dan peristiwa itu terasa menekan jiwanya. Remaja putri akan lebih cemas menghadapi menarche.

Hendro (2006) mengatakan lingkungan merupakan faktor yang mempengaruhi kecemasan. Informasi yang keliru dari lingkungan akan mengakibatkan timbulnya kecemasan dan ketakutan pada remaja putri sehingga secara tidak sadar ia akan menolak proses fisiologis menstruasinya. Selain itu keadaan fisik juga berpengaruh, dengan adanya menarche remaja putri akan mengalami perubahan perubahan pada dirinya sehingga menimbulkan kecemasan. Dukungan keluarga, sangat membantu meringankan beban kecemasan remaja putri yang menghadapi menarche. Karena fungsi keluarga sebagai sistem pendukung bagi anggotanya, dan anggota keluarga memandang bahwa orang yang bersifat mendukung, membantu selalu siap memberikan pertolongan dan bantuan jika diperlukan dalam menghadapi suatu permasalahan (Friedman, 2010).

Hasil penelitian tidak menemukan responden yang mengalami tingkat kecemasan panik. Hal ini karena responden tidak merasa ada gangguan pencernaan atau sakit perut, mengalami sering buang air kecil saat awal mengalami menstruasi, tidak menemui kesulitan untuk tidur nyenyak, dan merasakan kesemutan dijarijari tangan dan kaki saat mengalami haid pertama kali.

\section{KESIMPULAN}

Berdasarkan hasil penelitian maka dapat disimpulkan bahwa mayoritas tingkat kecemasan remaja dalam menghadapi menarche katagori kecemasan ringan, dan penyebab kecemasan yang dirasakan siswa karena duduk tidak nyaman, mimpi yang tidak enak dan tidak nyaman dengan pembalut yang tebal.

\section{SARAN}

1. Puskesmas hendaknya mengembangkan promosi kesehatan melalui penyuluhan kesehatan secara berkala kepada Siswi SMP IT Khalissaturrahmi Binjai tentang kesehatan reproduksi tentang menarche pada anak sekolah.

2. Pihak Sekolah diharapkan memberikan materi tambahan tentang kesehatan reproduksi khususnya tentang menarche. 
3. Diharapkan siswa SMP IT Kholissaturrahmi agar mencari informasi tentang menarche melalui media massa atau informasi dari guru sekolah.

4. Peneliti selanjutnya agar dapat melakukan penelitian lanjutan dan fokus pada penanganan menarche remaja.

\section{DAFTAR PUSTAKA}

Al-Mighwar, Muhammad.

Psikologi Remaja Petunjuk bagi Guru dan Orang Tua. Bandung: Pustaka Setia

Batubara. J.R.L. (2010) Adolescent Development (Perkembangan Remaja). Sari Pediatri Vol. 12.

Fauzi.S.A dan Irfan .S. (2017) Gambaran Tingkat kecemasan siswi menghadapi

menarche diMTS Nurul fata kabupa ten Purwakarta http://ejurnal.stikes bhaktikencana.ac.id

Hawari, (2006) Manajemen Steres Dan Cemas Dan Depresi, Edisi Kesahi, Cetakan Ketiga. Jakarta : Balai Penerbit FKUI.

Hendro, Tedi (2006) Perbedaan kecemasan pada remaja putri sebelum dan sesudah diberikaninformasi mengenai menstruasi pertama, http://tedihendro.com/?pg=article $s \&$ article/2006=2287, Diakses tanggal 10 April 2019.

Herpanes, (2012) Hubungan Antara Saiaran Televisi Status Gizi Terhadap Status Menrche Pada Siswi SMP Negeri 5 Tinambung Kabupaten Polma. Jurnal Dunia Gizi Pangan. Vol XIII,edisi 1 hal 36.
Kurniawan. (2009) Pengaruh Pendidikan Kesehatan Terhadap Tingkat Kecemasan Dalam Menghadapi Menarche Pada Siswi SD Negeri 1 Gayam Kabupaten Sukoharjo. Universitas Muhammadiyah Sukarta.

Mansur, Herawati dan Temu Budiarti. (2014) Psikologi Ibu dan Anak Jakarta: Salemba Medika. Novianti, Yasnani, dan Erawan. (2016) Hubungan Pengetahuan, Sikap, Dan Tindakan Dengan Personal Hygiene Menstruasi Pada Remaja Putri Di SMP Negeri Satap Bukit Asri Kabupaten Buton Fakultas Kesehatan Masyarakat Universitas Halu Oleo. Artikel.

Nugraha, (2011) Pengetahuan Dan Sikap Ibu Dalam Menghadapi Menarche Pada Remaja Putri di Lingkungan $\mathrm{X}$ Kelurahan Bandar Selamat Kec. Medan Tembung Tahun 2012. Fkep USU.

Purba M.J.,Dkk, (2010) Asuhan Keperawatan Pada Klien Dengan Masalah Psikososial dan Gangguan Jiwa. Medan: Press.T., USU.

Pertiwi. I. T dan Megatsari. H. (2015) Gambaran Tingkat Pengetahuan

Dan Praktik Menstrual Hygiene Siswi SDN 4 Pacarkembang Surabaya : FKM Universitas Airlangga Surabaya Jurnal Promkes Vol. 6 No. 2 Desember 2018 : 142 154

Proverawati, 2009, Menarche Menstruasi Pertama Penuh Makna. Yogyakarta: Muha Medika.

Retnaningsih.D.,dkk (2016) Kesiapan Menghadapi Menarche Dengan Tingkat Kecemasan Pada Anak Usia Sekolah Program Studi Ners STIKES Widya Husada Semarang 
Jurnal Kesehatan Kusuma Husada Januari 2018.

Saringendyanti, (2001) Pendidikan Sexs

Untuk Remaja. Puspa Swara :

Jakarta.

Stuart GW, Sundeen, (1998) Principles

and Practice of Psykiatric Nursing

(5 th ed.). St. Louis Mosby Year

Book.

Sumarsih.T., Nurfadillah.M, \&Asti .D.A (2018) Anxiety Levels

During Menarche Among Female Students At State Junior High School 1 Of Ayah, ) Program Studi Keperawatan, STIKES Muhammadiyah Gombong Jurnal Ilmiah Kesehatan Keperawatan Available online at: Volume $14 \mathrm{No}$ 2 Juni 2018

Suryani, E. \& Widyasih, H. 2008. Psikologi Ibu dan Anak. Yogyakarta : Fitramaya

Wijayanti N.C dkk.(2013) Hubungan Pengetahuan Remaja Tentang Menarche Dengan Kecemasan Menghadapi Menarche Di SD Tlogo Kasihan Dan SD Mejing Ii Gamping Yogyakarta Program Studi Ilmu Keperawatan Sekolah Tinggi Ilmu Kesehatan Jendral Achmad Yani Yogyakarta Wiknjosastro (2009) Buku panduan Praktis Pelayanan Kesehatan Maternal dan Neonatal, Edisi 1. Cet. 12. Jakarta : Bina Pustaka

World Organization Health. (2017). Menstruation and The Menstrual Cycle. (Diakses pada tanggal 23 April 2019 pukul 14.30). 